\title{
A RELAÇÃO ENTRE ENTRETENIMENTO E EDUCAÇÃO NA FILOSOFIA DE ARISTŐTELES: EM BUSCA DE CRITÉRIOS PARA DEFINIR O PAPEL DO ENTRETENIMENTO NA EDUCAÇÃO BRASILEIRA CONTEMPORÂNEA
}

\author{
Leonardo Dias Avanço* \\ José Milton de Lima**
}

\section{Resumo}

O presente artigo acompanha a reflexão filosófica e educacional de Aristóteles acerca do tema do entretenimento, bem como tece considerações sobre o papel dos entretenimentos na sociedade brasileira contemporânea. Busca responder às seguintes questões: como Aristóteles concebeu a relação entre entretenimento $e$ educação e como devemos dimensionar a relação entre entretenimento $e$ educação pública brasileira de um ponto de vista contemporâneo?

Palavras-chave: entretenimento, educação, filosofia, Aristóteles, sociedade brasileira.

\section{Resumen}

Este artículo examina el pensamiento filosófico y educativo de Aristóteles sobre el tema del entretenimiento, y presenta consideraciones sobre el papel del mismo en la sociedad brasileña contemporánea. Trata de responder a las siguientes preguntas: ¿cómo Aristóteles concibe la relación entre la educación e el entretenimiento, y como debemos planificar la relación entre el entretenimiento y la educación pública brasileña de un punto de vista contemporáneo?

Palabras clave: entretenimiento, educación, filosofía, Aristóteles, sociedad brasileña.

\section{Introdução}

Eu vivo em tempos sombrios.

Uma linguagem sem malícia é sinal de estupidez,

Uma testa sem ruga é sinal de indiferença.

Aquele que ainda ri é porque ainda não recebeu a terrível notícia.

\section{Bertold Brecht}

\footnotetext{
" Professor dos cursos de Educação Física e de Direito da Faculdade de Presidente Prudente (FAPEPE - UNIESP); Doutorando em Educação pela Faculdade de Ciências e Tecnologia de Presidente Prudente (FCT - UNESP). E-mail: ldavanco87@gmail.com

** Professor Assistente Doutor do Departamento de Educação e do Programa de Pós-Graduação em Educação da Faculdade de Ciências e Tecnologia de Presidente Prudente (FCT - UNESP). E-mail: miltonlima@fct.unesp.br
}

AVANÇO, Leonardo Dias; LIMA, José Milton de Lima. A relação entre entretenimento e educação na filosofia de Aristóteles: em busca de critérios para definir o papel do entretenimento na educação brasileira contemporânea. Revista Sul-Americana de Filosofia e Educação. Número 23: nov/2014-abr/2015, p. 149-171. 
O consumo de entretenimentos constitui-se em um dos elementos reprodutores do espetáculo na sociedade moderna. E o que é o espetáculo? Segundo Debord, o espetáculo “[...] não é um conjunto de imagens, mas uma relação social entre pessoas, mediada por imagens" (DEBORD, 1997, p. 14). Tais imagens, monopolizadas pelo capital financeiro $e$ industrial, impõem-se como idênticas à realidade, como se a realidade não fosse algo mais do que aquilo que se nos aparece espontânea e intuitivamente. Portanto, o consumo de entretenimentos reproduz imagens que mediatizam as relações sociais, mediação essa que assume um caráter simultaneamente ludibriador e normativo. Ludibriador no sentido de identificar realidade e aparência. Normativo no sentido de ditar o que as pessoas devem pensar e como pensar, sentir e como sentir, valorar e como valorar, e fazer e como fazer.

No Brasil, a indústria do entretenimento tem exercido um enorme poder, seja no campo da música, do esporte, da literatura, do cinema, dos programas de talk show e de reality show ou mesmo das telenovelas. Nos dois últimos anos, os meios de comunicação de massa tradicionais promoveram de maneira especial, mediante transmissão televisiva, os megaeventos esportivos que ocorreram no Brasil $^{1}$. Como se não bastasse a exibição de dois ou três jogos da Copa do Mundo da FIFA 2014 por dia, a Rede Globo ${ }^{2}$ insistiu em promover tal megaevento em seus telejornais e programas mais variados. Durante o horário comercial das transmissões, o capital financeiro e o capital industrial promoveram conjuntamente um festival de propagandas de conteúdo ufanista e reacionário. Enquanto isso, em conluio com a grande mídia, o governo brasileiro continua a dar declarações extremamente vagas quando questionado sobre o número exato de famílias que foram irregularmente desalojadas de seus lares, vítimas da especulação imobiliária resultante das obras dos megaeventos.

Compreender a função que a indústria do entretenimento cumpre no contexto histórico brasileiro atual se constitui em uma tarefa imprescindível. A fim

\footnotetext{
${ }^{1}$ Copa das Confederações FIFA 2013 e Copa do Mundo FIFA 2014.

${ }^{2}$ Conglomerado midiático que opera no Brasil desde 1965.
} 
de que expressássemos as motivações que nos levaram à construção do presente artigo, foi-nos necessário, já na introdução, expor o fenômeno contemporâneo que nos tem chamado a atenção. Porém, não pretendemos, no presente momento, demonstrar desdobramentos mais profundos do funcionamento da indústria do entretenimento. Pretendemos, antes disso, desenvolver uma importante, porém pouco discutida, reflexão no âmbito da Filosofia da Educação, qual seja, a reflexão sobre o conceito de entretenimento e sobre sua relação com a educação.

Do ponto de vista da ordem da exposição, primeiramente, a relação entre entretenimento e educação foi abordada segundo o ponto de vista aristotélico, de modo que, elaborados alguns conceitos filosóficos, posteriormente, foi retomada a análise sobre a função do entretenimento na sociedade brasileira atual. Escolhemos o ponto de vista aristotélico por termos notado a sua indelével influência na história da filosofia ocidental.

Em primeiro lugar, expomos o conceito de entretenimento desenvolvido na Ética a Nicômaco. Em segundo lugar, demonstramos a relações entre entretenimento e educação em $A$ política. Por fim, não deixando de fazer as devidas críticas às propostas de Aristóteles, retomamos as discussões iniciadas na presente introdução com o fito de apreender o papel do entretenimento na educação brasileira contemporânea.

Esse trajeto nos permitiu responder às seguintes questões: como Aristóteles concebeu a relação entre entretenimento e educação e como devemos dimensionar a relação entre entretenimento e educação pública brasileira de um ponto de vista contemporâneo? Tais questões, não obstante, constituem o problema central sobre o qual versam as reflexões do presente artigo.

\section{Conceito de entretenimento na Ética a Nicômaco de Aristóteles}

Para que se compreenda o conceito de entretenimento na filosofia de Aristóteles, faz-se necessário antes de tudo elaborar algumas distinções semânticas.

No português, as palavras "jogo" e "entretenimento" podem ser tradicionalmente entendidas como termos sinônimos. O tema do entretenimento 
aparece tanto na Ética a Nicômaco quanto em $A$ política de Aristóteles e, no contexto dessas obras, o termo grego empregado pelo filósofo é diagoguê $(\delta\llcorner\alpha \gamma \omega \gamma \eta)$. Ao contrário do que acontece no idioma português, a palavra diagoguê não é sinônima do termo paidia $(\pi \alpha \iota \delta \iota \alpha)$, isto é, jogo.

A fim de que melhor fundamentemos a ideia anterior, vejamos como Huizinga formulou a distinção do termo diagoguê. Para o historiador neerlandês, há no pensamento grego:

"[...] um obstáculo constituído pela peculiaridade semântica a que anteriormente fizemos referência, o fato de a palavra que designa o jogo - $\pi \alpha \mathrm{t} \delta \mathrm{\imath} \alpha$ - ser sempre, devido a sua etimologia, tomada no sentido de jogo de crianças, de infantilidade. Portanto, foi preciso que as formas mais elevadas fossem expressas por termos específicos como ó $\gamma \omega \dot{v} v$,

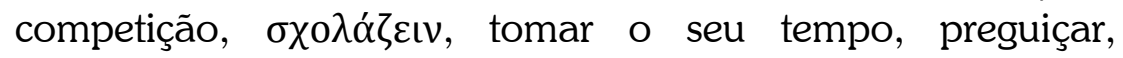
$\delta\llcorner\alpha \gamma \omega \gamma \eta$ (à letra, "passar", mas, de maneira aproximada, podendo ser traduzido como "passatempo", palavras de onde se encontra inteiramente ausente o elemento lúdico essencial)" (HUIZINGA, 2009, p. 178-179).

Os gregos possuíam uma necessidade de distinguir o infantil do adulto, do mesmo modo como se distingue o imperfeito do perfeito, o incompleto do completo. Por essa razão, os gregos cunharam palavras de radicais distintos para exprimir fenômenos que, para nós, são abarcados por um mesmo termo, qual seja, o termo "jogo". Como se pode notar na citação acima, enquanto o termo paidia sempre denota algo relativo à infância, a palavra diagoguê nem sempre o faz. Aliás, quando se refere aos entretenimentos (diagoguê), Aristóteles pensa no homem formado, isto é, no adulto (AVANÇO, 2012, p. 13).

Quando, no livro X da Ética a Nicômaco, Aristóteles introduziu o tema da relação entre entretenimento e felicidade (isto é, da relação entre diagoguê e eudaimonia), o filósofo referiu-se ao entretenimento não como um tipo de atividade, mas sim como uma espécie de ocupação. Não obstante, para Aristóteles, nem toda ocupação seria atividade, visto que existiriam ocupações passivas. No português, normalmente, entende-se a palavra jogo como uma espécie de atividade. Por essa razão, decidimos traduzir a palavra diagoguê por 
entretenimento, mas ela também pode ser entendida como passatempo ou recreação. Tais vocábulos evocam as noções de distração, descanso, recuperação, noções que possuem maior afinidade com o significado de diagoguê na filosofia aristotélica.

Portanto, é no interior do específico contexto semântico até o momento abordado que desejamos apresentar as ideias de Aristóteles acerca da relação entre entretenimento e educação. Feitas as distinções semânticas imprescindíveis, faz-se necessário retomar a clássica divisão dos gêneros de atividade humana na perspectiva da filosofia aristotélica, de modo que compreendamos a razão de Aristóteles não classificar os entretenimentos no gênero das atividades.

Para Aristóteles, toda atividade se liga ao emprego da razão. Nesse sentido, os demais animais não são capazes de realizar atividades, visto que não são racionais. Ademais, não existe um emprego único da razão, uma vez que a vida humana não é simples, mas complexa. De acordo com os vários modos de emprego da razão, desdobram-se diferentes gêneros de atividade humana.

De um modo geral, segundo Aristóteles, a razão humana possui três funções, a saber: uma função teorética, uma função prática e uma função produtiva (ARISTÓTELES, 1969, p. 141-142). A manifestação da função teorética da razão é a especulação teórica; a manifestação da função prática da razão é a ação virtuosa (aretê); e a manifestação da função produtiva da razão são as artes. Na realidade, todos os resultados do emprego da razão desembocam em ciências, sejam elas teoréticas, práticas ou produtivas, mas, para Aristóteles, a ciência entendida em sentido principal é a ciência teorética. Vejamos, parte a parte, as características das três funções da razão.

A função teorética da razão manifesta-se na especulação teórica. Essa função se caracteriza pelo emprego da razão na descrição da ordem da natureza, na investigação das leis do pensamento e no exame dos primeiros princípios cosmológicos. Enquanto descrição da ordem da natureza, a razão elabora a Física, ou Filosofia Segunda, que investiga o mundo natural, abrangendo os seres animados e inanimados. Enquanto investigação das leis do pensamento, a razão sistematiza a Lógica, isto é, o instrumento propedêutico de todas as demais 
ciências. Por fim, enquanto exame dos primeiros princípios cosmológicos, a razão erige a Metafísica, ou Filosofia Primeira, que investiga os primeiros princípios de todas as coisas. Na especulação teórica, a atividade desenvolver-se-ia em toda a sua plenitude e produziria um conhecimento seguro, visto que se vincularia a tudo aquilo que necessariamente é.

A função prática da razão manifesta-se na ação virtuosa. Essa função se caracteriza pelo emprego da razão na elaboração de princípios que abrangem todas as esferas de inter-relações humanas. Nesse sentido, a Ética e a Política são as áreas do conhecimento humano que correspondem às funções práticas da razão. Do ponto de vista da Ética, a razão cumpre a função de delimitar a ação justa e virtuosa em diversas situações contingentes, exigindo-se do homem o desenvolvimento de uma conduta prudente. Do ponto de vista da Política, a razão cumpre a função de planejar e executar, no interior de condições também contingentes, ações que façam do Estado o instrumento da felicidade coletiva dos cidadãos. Na ação virtuosa, a atividade não elaboraria um conhecimento tão seguro quanto o conhecimento das ciências teóricas, visto que não lidaria com aquilo que sempre é, mas com aquilo que pode ser.

A função produtiva da razão manifesta-se na criação artística. Essa função se caracteriza pelo emprego da razão na elaboração de técnicas específicas a cada área da expressão artística. Deve-se entender a arte, no pensamento aristotélico, em sentido lato, visto que ela se refere a tudo aquilo que é produto da atividade produtiva humana, tal como, por exemplo, a construção civil, a olaria, a culinária, a arquitetura, a pintura, a medicina, em suma, todo aquele conhecimento de que depende o uso de nosso corpo, em especial, de nossas mãos ${ }^{3}$. Algumas artes, não obstante, visam à utilidade, tal como, por exemplo, a medicina, enquanto outras artes aspiram à beleza, tal como, por exemplo, a música. Entretanto, tanto a música quanto a medicina são conhecimentos que se expressam na produção, isto é, conhecimentos que se mostram por meio de habilidades corporais. Na criação artística, assim como na ação virtuosa, a razão não produziria conhecimentos

\footnotetext{
${ }^{3}$ Não se devem excluir outras partes do corpo. O samba e o futebol, por exemplo, exigem o desenvolvimento de técnicas ligadas ao emprego dos pés.
} 
seguros, já que lidaria com a contingência e não com a necessidade dos acontecimentos.

Aristóteles observava a natureza e induzia uma ordem cíclica dos acontecimentos. Essa ordem permitiria à especulação teórica, caso fosse rigorosamente aplicada, o estabelecimento de um conhecimento seguro, porque os eventos cíclicos naturais ocorreriam sempre e necessariamente da mesma forma em épocas passadas, presentes e futuras. Essa mesma ordem, entretanto, não era observada nos conhecimentos dos eventos que dependiam da opção humana para se desencadearem, tais como seriam, por exemplo, os casos da ação virtuosa ou da atividade produtiva. Nesses últimos casos, o conhecimento humano não obedeceria a uma lei necessária, cíclica e universal, visto que dependeria da contingência, isto é, de acontecimentos que podem ou não acontecer, segundo a escolha dos homens. Ora, o movimento do sol não depende da escolha dos homens, mas a construção de um navio depende.

Como é possível notar na classificação de e na comparação entre os gêneros de atividade humana, os entretenimentos não se encaixam em nenhuma classe de atividade.

Mas alguém poderia fazer a seguinte contestação: a música é um gênero de entretenimento $e$, não obstante, classifica-se entre as atividades produtivas. Para solucionar esse problema, devemos observar que, na perspectiva de Aristóteles, a música é um gênero de entretenimento, mas não no sentido de quem a produz, isto é, do artista, mas no sentido de quem a aprecia, ou seja, do espectador. Ainda assim, o contestador poderia levantar a seguinte objeção: a apreciação não é uma característica exclusiva daquele que é espectador da música, visto que aquele que a produz, isto é, o artista, também a aprecia no momento em que a produz. Nesse sentido, sendo a apreciação um acompanhamento da atividade (no caso, da atividade produtiva), não podemos entendê-la como qualidade diferenciadora dos entretenimentos. Ademais, aquele que se dedica ao pensamento filosófico aprecia o que faz, pois o faz com espontaneidade, assim como aquele que age de maneira verdadeiramente virtuosa, isto é, aquele que age não por coação ou medo, mas 
por livre opção racional. Logo, para o contestador, a definição de entretenimento deveria trilhar por outro caminho.

A fim de dar uma solução ao problema acima apresentado, não precisamos modificar totalmente o percurso da exposição, visto que estamos próximos da definição aristotélica de entretenimento. Contudo, talvez precisássemos distinguir os gêneros de apreciação existentes, pois, para Aristóteles, a apreciação, a satisfação ou o prazer experimentado na atividade é de natureza radicalmente distinta da apreciação, da satisfação ou do prazer experimentado nos entretenimentos. Essa distinção nos pode ajudar a entender com mais clareza o lugar do entretenimento na vida humana segundo o filósofo.

Portanto, para Aristóteles, existem duas espécies de prazeres, a saber: por um lado, os prazeres mesclados ou restaurativos; por outro, os prazeres puros ou estimulantes.

Os prazeres mesclados ou restaurativos seriam aqueles ligados à fadiga, à necessidade, à limitação corpórea do ser humano. Vejamos alguns exemplos: enquanto estamos sonolentos, é um prazer dormirmos; enquanto estamos famintos, é um prazer comermos; enquanto estamos sedentos, é um prazer bebermos; enquanto estamos exaustos de tanto nos dedicarmos à atividade (seja ela especulativa, prática ou produtiva), é um prazer nos divertirmos ou nos entretermos.

Já os prazeres puros ou estimulantes seriam aqueles que acompanham a atividade, estimulando-a, funcionando como algo análogo ao "que sobrevém como a exuberância da saúde nos jovens e vigorosos" (ARISTÓTELES, 2009b, p. 291), isto é, algo semelhante a um estímulo viçoso que prolonga a atividade. Como as atividades humanas são múltiplas, para cada tipo específico de atividade corresponderia uma espécie de prazer estimulante. O músico seria estimulado pela audição, o pintor seria estimulado pela visão, o filósofo seria estimulado pela razão e assim por diante.

No contexto filosófico da definição de entretenimento, Aristóteles, no livro X da Ética a Nicômaco, ocupava-se da exposição do gênero de vida que estivesse em harmonia com a verdadeira felicidade (eudaimonia). Ora, se não fosse atividade, 
mas uma espécie de ocupação passiva, espectadora, o entretenimento então não se ligaria ao emprego razão. Não se ligando ao emprego da razão, isto é, da qualidade que diferenciaria os homens dos demais animais e os aproximaria da divindade $e^{4}$ o entretenimento não poderia, de acordo com os pressupostos filosóficos de Aristóteles, identificar-se com a verdadeira felicidade. Portanto, um gênero de vida dedicado aos entretenimentos, embora fosse considerado o mais feliz pela maior parte das pessoas, não se poderia confundir com o gênero de vida verdadeiramente feliz.

Para Aristóteles, por um lado, a felicidade acompanharia a própria atividade especulativa; por outro, a felicidade seria um composto de bens do corpo (saúde, beleza, condicionamento físico etc.), bens materiais (riqueza, sorte etc.) e bens da alma (virtudes morais e intelectuais) (ARISTÓTELES, 2009b, p. 52). Nesse sentido, o gênero de vida mais feliz seria aquele dedicado à contemplação filosófica, mas para apreciá-la seria necessário ser livre (isto é, não escravo), saudável, não sofrer reveses da sorte, não se dedicar a atividades degradantes (produtivas) e ser educado, desde cedo, a tomar gosto pelas virtudes morais e intelectuais.

Entretanto, segundo o filósofo, o homem seria incapaz de dedicar-se durante todo o tempo à atividade especulativa, porquanto existiria a fadiga. Somente a divindade teria esse "privilégio" $e$, por conseguinte, somente ela seria sumamente feliz. O homem seria um composto de corpo e intelecto e, portanto, teria acesso à felicidade, mas tal acesso seria restrito pelas limitações de sua dimensão corpórea e animal. Visto que sentiria necessidades e se abateria pela fadiga, o homem precisaria dedicar-se a outros tipos de ocupações diferentes da atividade. Foi nesse contexto que Aristóteles identificou o papel do entretenimento na vida do homem verdadeiramente feliz. Nas palavras do próprio filósofo:

"Afinal, o entretenimento é uma forma de repouso, mas precisamos repousar porque não somos capazes de trabalhar ininterruptamente, o que evidencia que não é um fim, visto

\footnotetext{
${ }^{4}$ É preciso lembrar que a metafísica aristotélica classificava a divindade ou o Primeiro Motor Imóvel no gênero dos seres vivos. Além disso, o Primeiro Motor Imóvel seria perfeito, porque imutável; pura atividade de pensamento que contempla a si mesmo.
} 
que o empregamos como um meio para o prosseguimento da atividade" (ARISTÓTELES, 2009b, p. 305-306).

Como se pode notar na citação acima, o entretenimento não seria um fim, mas um meio. Isso quer dizer que não deveríamos buscá-lo como a identificação com a felicidade, mas deveríamos fazer uso do mesmo como forma de descanso, para o posterior retorno à atividade. Enquanto repouso, o entretenimento seria uma ocupação passiva que proporciona um prazer mesclado e restaurativo, visto que não estimularia a atividade, mas prepararia o corpo e a alma para a posterior retomada do exercício da mesma.

Definido o conceito de entretenimento, abordemos agora a análise de Aristóteles acerca de sua relação com a educação.

\section{A relação entre entretenimento e educação em $A$ política de Aristóteles}

A relação entre entretenimento e educação foi abordada no Livro VIII de $A$ política, livro esse que dá continuidade à exposição da cidade ideal ${ }^{5}$, enfocando mais especificamente a formação educacional do cidadão livre que a habitaria.

Em suas reflexões sobre a educação, Aristóteles levou em consideração o desenvolvimento natural da criança. Com efeito, o filósofo concebia que, durante os primeiros anos da infância do homem, a razão permaneceria adormecida. $\mathrm{Na}$ ordem da procriação, "o corpo está antes da alma, assim como a parte irracional está antes da parte racional" (ARISTÓTELES, 2009a, p. 259-260). Portanto, o corpo da criança, na perspectiva acima adotada, deveria ser objeto da educação em primeiro lugar. Diante dessa constatação, o filósofo propôs uma série de etapas da educação, segundo o nível de desenvolvimento natural da criança.

Não obstante, o estadista, que também seria um educador, deveria prescrever as regras da união conjugal, visto que da combinação sexual de

\footnotetext{
${ }^{5}$ Como considerava que a política envolvesse uma espécie de arte, e como entendia a arte como uma forma imperfeita de conhecimento (visto que lidaria com o contingente), Aristóteles acreditava que a filosofia pudesse colaborar elaborando as condições ideais do produto da arte política, mesmo que tais condições fossem inatingíveis na realidade. Desse modo, embasando-se na filosofia política, o político poderia, ao menos, trabalhar no sentido de se aproximar ao máximo da perfeição.
} 
determinados corpos de homens e mulheres resultaria determinada conformação corporal dos filhos. Nessa perspectiva, não seria recomendável permitir que pessoas muito jovens tivessem filhos, visto que se acreditava na tendência de que, em casos como esses, os filhos nascessem fracos, de pequena estatura, imperfeitos e do sexo feminino ${ }^{6}$.

Ademais, Aristóteles teceu uma série de considerações muito curiosas sobre a idade ideal do homem $e$ da mulher para o casamento $e$ a procriação, bem como se mostrou à frente de seu tempo quando percebeu a importância do estado de ânimo das gestantes no que se refere à formação intrauterina do bebê. Entretanto, não aprofundaremos esses assuntos, buscando expor, em conveniência aos objetivos do presente artigo, as características da educação após o nascimento da criança.

Durante o período de aproximadamente zero a dois anos de idade, Aristóteles entendia que a alimentação deveria ser a principal fonte de preocupação da família, a qual teria um importante papel educacional. Nessa perspectiva, o filósofo prescrevia o leite materno como o principal alimento para esse período do desenvolvimento. De resto, bastava que os pais deixassem livres os movimentos das crianças, bem como não se incomodassem com o choro das mesmas, visto que tais manifestações naturais seriam benéficas ao desenvolvimento de seus corpos.

Durante o período de aproximadamente dois a cinco anos de idade, Aristóteles propunha, por um lado, a continuidade da educação corporal; por outro, o incentivo à prática das virtudes morais. Relativamente à educação corporal, movimentos excessivamente pesados não seriam permitidos às crianças livres. Nesse sentido, tais crianças adotariam um regime de exercícios físicos que não fossem nem muito fatigantes, nem de exagerada facilidade, mas exercícios convenientes a homens livres. Relativamente à prática das virtudes morais, os jogos de imitação seriam prescritos às crianças livres, desde que as mesmas não fossem influenciadas pelos hábitos dos escravos. Para evitar o contato das crianças livres

\footnotetext{
${ }^{6}$ É sabido nível de repressão à mulher na Grécia Antiga. Visto que eram vistas como naturalmente inferiores aos homens, as mulheres não eram consideradas cidadãs nem mesmo por Aristóteles.
} 
com escravos, Aristóteles propunha a nomeação de magistrados aptos a vigiar $e$ fiscalizar as ocupações de tais crianças. Se a formação das virtudes morais se iniciaria com a imitação daquilo que se considerava como "bons comportamentos", então as crianças livres não poderiam ficar indiscriminadamente na companhia de homens não-livres.

Durante o período de aproximadamente cinco a sete anos de idade, a principal mudança pedagógica proposta por Aristóteles consistiu no incentivo a que as crianças livres menores frequentassem os espaços os quais as crianças livres mais velhas já frequentavam. Entretanto, não seria permitido àquelas as mesmas ocupações que a estas. Sendo assim, as crianças livres menores assumiriam o papel de espectadoras. Aristóteles acreditava que, com esse incentivo, a criança livre desse período do desenvolvimento seria estimulada a realizar atividades que fariam no futuro, estímulo esse que enriqueceria seus jogos de imitação. Nesse sentido, a educação ainda assumiria a função de dar uma conformação corporal saudável $e$ formar os hábitos virtuosos na criança livre.

Até o momento, a educação não foi pensada no âmbito do Estado. Por enquanto, foram mencionados os magistrados aptos a vigiarem as crianças livres $e$ a família como os principais protagonistas educacionais. Não foi sequer mencionado o ensino de ciências. Não obstante, o período subsequente, que abrange aproximadamente as idades de sete a quatorze anos, traz uma importante modificação. Vejamos, nas palavras do próprio filósofo, que mudança seria essa:

"Mas como existe um objetivo único para a cidade, segue-se que a educação também deve ser única para todos, administrada em comum, e não entregue aos particulares, como se faz hoje dirigindo cada qual a educação dos filhos, $e$ dando-lhes o gênero de instrução que melhor lhe parece. No entanto, aquilo que é comum a todos deve também ser aprendido em comum" (ARISTÓTELES, 2009a, p. 267). 
É nessa etapa da educação em comum ${ }^{7}$, dirigida pelo Estado, que o tema da relação entre educação e entretenimento adquire toda sua relevância. Sem embargo, Aristóteles distinguiu três partes da educação em comum, a saber: 1) a prática da virtude moral; 2) o ensino das artes úteis à vida; e 3) a arte da recreação ou do entretenimento. Como já nos referimos à prática da virtude moral, foquemos nossa exposição nos dois últimos tópicos.

Relativamente às artes úteis à vida, em consonância com o currículo do sistema educacional de sua época, Aristóteles prescreveu a gramática, o desenho, a ginástica e a música. Entendia-se que a gramática fosse útil à vida à medida que permitia aos homens livres a execução de uma série de tarefas cotidianas. No entanto, a gramática também serviria à construção de outros conhecimentos, o que tornava indispensável o seu ensino. Ademais, compreendia-se que o desenho cumpriria a função de permitir que a criança experimentasse uma visão mais delicada da beleza da natureza. Com efeito, o desenho seria muito importante para o desenvolvimento do gosto pela observação contemplativa da natureza, prática essa fundamental à filosofia. Além disso, assumia-se que a ginástica fosse extremamente útil, cumprindo uma função na manutenção da saúde e do condicionamento físico. Para tanto, obedecendo à mesma fórmula anteriormente mencionada, os exercícios físicos prescritos às crianças livres deveriam ser convenientes à liberdade que lhes seria própria.

Relativamente à música, façamos agora uma exposição mais pormenorizada, visto que a partir deste momento passamos a adentrar na específica problemática que nos compete compreender.

Enquanto os contemporâneos do filósofo prescreviam a música como um entretenimento, os sábios de épocas mais antigas, segundo o seu próprio relato, prescreviam-na como uma ciência a ser obrigatoriamente ensinada. Diante dessa diversidade de abordagens sobre o papel da música na educação, Aristóteles iniciou a investigação de cada uma delas: "o primeiro ponto é saber se ela deve fazer parte da educação, ou se deve ser excluída, e se é uma ciência, um prazer, ou

\footnotetext{
${ }^{7}$ É preciso que nos lembremos de que se trata de uma educação para crianças e adolescentes livres e, portanto, não-bárbaros e/ou não-escravos.
} 
um simples passatempo. Ora, é com razão que se lhe dão essas três denominações, e ela parece reunir todas três" (ARISTÓTELES, 2009a, p. 274).

Entendida como prazer, reconheceu-se que a sua função para o homem livre seria o descanso: "porque o prazer tem por fim o descanso, e todo descanso é forçosamente agradável, visto que é uma espécie de remédio contra a fadiga produzida pelo trabalho". A definição de música como prazer, por conseguinte, é abrangida pela definição de música como entretenimento, isto é, como descanso. Diante dessa condição, bastava definir se a música deveria ser trabalhada na educação como entretenimento ou como ciência. Qual seria a definição substancial da música? Para responder a essa questão, seria necessário levar em consideração dois critérios.

O primeiro critério consiste no grau de importância conferido à música na educação. Nesse sentido, dado que a atividade seria superior ao descanso e dado que a ciência seria resultado da atividade, então a definição substancial de música a classificaria no gênero das ciências.

O segundo critério seria o da conveniência. Esse critério foi aplicado originalmente por Aristóteles na investigação das harmonias musicais convenientes a cada etapa da vida. No entanto, nós também o podemos empregar, no interior do sistema filosófico aristotélico, para avaliar se o aprendizado da música convém aos adultos ou às crianças (AVANÇO, 2012, p. 94). Portanto, como, para Aristóteles, conviria à criança livre aprender a música com a finalidade de desfrutála enquanto entretenimento na idade adulta, e como o fim seria mais valioso que o meio, então a definição substancial de música a enquadraria primordialmente no gênero dos entretenimentos e não no das ciências. Ora, no início do tópico anterior, vimos que o adulto era considerado superior à criança.

Interessa-nos, no presente artigo, explorar a definição de música como entretenimento, de acordo com o segundo critério. Vejamos o que a esse respeito nos disse Hourdakis:

"Eis por que é necessário que os jovens a aprendam de maneira prática enquanto são jovens, de modo que, quando crescerem, após terem abandonado sua prática, estejam em 
condições de julgar a boa música e usufruí-la, graças à cultura que adquiriram na juventude" (HOURDAKIS, 2001, p. 41).

De acordo com essa análise, do ponto de vista da função da música, podese dizer que, para Aristóteles, a relação entre educação e entretenimento não é direta, mas indireta. Ora, se todo entretenimento seria descanso, e se toda educação seria uma arte (isto é, uma atividade), não poderíamos relacionar diretamente entretenimento e educação. Constituem uma relação indireta no sentido de que a música deveria ser ensinada às crianças enquanto arte, mas não para que o cidadão livre, um adulto formado, fosse um exímio músico, e sim para que ele soubesse desfrutar de um entretenimento honesto e superior, como seria o caso da música.

É preciso lembrar que, no contexto da filosofia ética e política de Aristóteles, as atividades produtivas são consideradas inferiores às atividades práticas $e$ especulativas. Nesse sentido, como no Livro VIII se discutia a educação do cidadão perfeito que habitaria a cidade ideal, Aristóteles não aprovava que tal cidadão se ocupasse de "atividades degradantes". Por essa razão, a música, enquanto ciência e atividade produtiva, seria reservada à infância. $\mathrm{O}$ cidadão, depois de formado, deveria ocupar-se somente de atividades valorosas, tais como a especulação filosófica, a prática das virtudes morais e a administração política da pólis.

Aliás, visto que Aristóteles entendia que a criança fosse incapaz de dedicarse à atividade por muito tempo, devido ao débil desenvolvimento de sua razão, a música compensaria o trabalho com a gramática, o desenho e a ginástica, visto que seria essencialmente prazerosa: "A juventude é precisamente a idade própria ao estudo dessa arte; porque é natural que os jovens não suportem aquilo que nada oferece de agradável" (ARISTÓTELES, 2009a, p. 277).

Ademais, o conhecimento musical que as crianças receberiam não se limitaria ao mero aprimoramento técnico. Aristóteles ocupou-se da teorização acerca das diferentes reações estéticas que experimentamos quando entramos em contato com diferentes harmonias. Os ouvidos humanos estariam capacitados a reproduzir sentimentos na alma em conformidade com as harmonias musicais experimentadas. Como, conforme já dissemos, buscava a formação da virtude por 
meio da educação, Aristóteles prescreveu a harmonia ${ }^{8}$ dórica para o ensino da música para as crianças e os adolescentes. Tal harmonia, associada aos cantos morais, despertaria sentimentos de paz e repouso. Os cantos práticos, aliados à harmonia frígia, por outro lado, seriam próprios para o entretenimento dos adultos, visto que tal harmonia despertaria o entusiasmo. Portanto, por meio do ensino da música, além da técnica, as crianças seriam impelidas a habituar-se à prática da virtude moral e, futuramente, ao gosto pelos "nobres entretenimentos".

Expostas as principais ideias acerca da relação entre entretenimento $e$ educação na filosofia de Aristóteles, passemos agora à retomada e ao aprofundamento das discussões que havíamos iniciado na introdução do presente artigo.

\section{A relação entre entretenimento e educação na contemporaneidade}

Seria absolutamente absurdo e despropositado defender a aplicação prática da teoria aristotélica acerca da relação entre entretenimento e educação na escola pública brasileira. A fim de que melhor esclareçamos essa ideia, exploremos, em primeiro lugar, as limitações dos pressupostos e das teses aristotélicos; posteriormente, reflitamos sobre o critério que a educação pública brasileira deve estabelecer a fim de se posicionar frente aos entretenimentos que vem sendo consumidos pelos alunos.

A primeira limitação das teses aristotélicas consiste no pressuposto assumido pelo filósofo de que toda civilização se funda na instituição da escravidão. Nessa perspectiva, a liberdade não seria entendida em sentido universal, mas sim como o privilégio da "comunidade dos livres", isto é, dos cidadãos gregos. Como é sabido, Aristóteles, em $A$ política, propunha que a escravidão fosse uma instituição natural. Defendia-se a ideia de que a raça dos gregos fosse superior às raças não-gregas, ou seja, ao conjunto de povos não conhecedores da língua, da religião, dos costumes e da organização política e econômica dos gregos. Com efeito, os gregos - homens

\footnotetext{
${ }^{8}$ Cada harmonia predisporia a alma de diferentes formas. A harmonia mixolídia, por exemplo, predisporia a alma à melancolia.
} 
supostamente livres por natureza - teriam o direito natural de escravizar os bárbaros - homens supostamente escravos por natureza.

Consideramos o pressuposto aristotélico acima apresentado como uma limitação à medida que, hoje, é demasiado fácil refutar, por meio da ciência e da lógica, os disparates das teorias racistas. O que não significa que tais teorias, na atualidade, não continuem cumprindo uma função deletéria. A paranoia fascista, por exemplo, continua sustentando que povos "racialmente superiores" possuem o direito de escravizar povos "racialmente inferiores" ou "miscigenados". Para citar dois casos contemporâneos, enquanto, por um lado, o euromaidan ${ }^{9}$, agitação civil ucraniana de caráter ultranacionalista, empreendeu um golpe de estado em fevereiro de 2014, golpe esse inspirado por um sentimento antirrusso exacerbado, por outro, os sionistas têm sistematicamente cometido extermínio genocida do povo palestino na Faixa de Gaza. Enquanto o racismo era tolerado entre a maioria dos gregos da época de Aristóteles e ainda é tolerado e praticado por muitos, nós o consideramos inaceitável.

A segunda limitação das teses aristotélicas reside na ideia de que existe uma espécie de hierarquia das atividades humanas. Essa hierarquia está fundamentada na ideia metafísica segundo a qual se afirma que o Primeiro Motor Imóvel, isto é, a divindade, seria o ser mais feliz dentre todos os seres, porque seria eternamente vivo, perfeito, imutável e puro pensamento que permanentemente pensa a si mesmo. Essa ideia de felicidade sustenta a concepção de que a atividade pensante ou especulativa, resultante da atitude contemplativa, seria a atividade que mais aproxima os homens da divindade e, por conseguinte, seria a atividade que se vincula diretamente à vida verdadeiramente feliz. Como essa concepção metafísica de Aristóteles, por ser metafísica, é destituída de provas e, por conseguinte, é descartável, não nos é permitido afirmar que a especulação filosófica seja uma forma de atividade superior à prática da virtude moral ou às atividades produtivas. Tampouco nos é permitido afirmar que o filósofo seria mais feliz que o músico, o arquiteto, o pintor, o cozinheiro. Essa limitação deriva do fato de o pensamento aristotélico ser a-histórico e idealista.

\footnotetext{
9 "Euro": abreviação de Europa. "Maidan": Praça de Independência de Kiev.
} 
A terceira limitação das teses aristotélicas consiste na defesa da ideia de que, por ser uma "atividade degradante", a música só deveria ser aprendida, enquanto arte, na infância, visto que, na idade adulta, o cidadão perfeito deveria ocupar-se de "atividades superiores", tais como, por exemplo, a contemplação filosófica e a administração política da cidade. Como vimos, o ensino da música seria recomendado para as crianças porque elas ainda não teriam desenvolvido o pensamento racional e, naturalmente, por essa razão, elas não poderiam desfrutar dos "prazeres puros". Essa concepção pressupõe que o homem livre não se ocuparia de atividades produtivas, visto que essas seriam relegadas a "homens inferiores", tais como, por exemplo, "escravos por natureza". Como a ideia de retorno à escravidão é execrável e as meditações metafísicas são infrutíferas, tornase impossível sustentar racionalmente, por um lado, a ideia de inferioridade das atividades produtivas (no caso, da música) e, por outro, a proposta de formação de um cidadão ideal que só se ocuparia de assuntos filosóficos e políticos, deixando a maior parte das atividades produtivas relegadas a escravos.

Não obstante as limitações acima apresentadas, a distinção aristotélica entre entretenimentos bons e entretenimentos ruins chama-nos a atenção. Razão pela qual, analisando um tema aparentemente frívolo, Aristóteles conferiu grande importância à definição do lugar dos entretenimentos na vida humana e na educação. Podemos questionar o critério aristotélico de distinção entre os entretenimentos bons e ruins, mas não podemos deixar de levar em consideração que a necessidade dessa distinção era e ainda é inteiramente legítima. Do ponto de vista contemporâneo, parece-nos de grande importância responder à seguinte questão: os produtos da indústria do entretenimento devem ou não devem ser desfrutados pelas crianças? É claro que pais e professores não têm o direito de privar as crianças do contato com a realidade, mas é evidente que eles têm o dever de encorajá-las a se interessarem por formas de entretenimento que não são alienantes.

Não podemos nos limitar, porém, a apresentar uma noção abstrata de criança quando falamos sobre a responsabilidade dos "pais" e dos "professores" para com "as crianças". A sociedade brasileira é ampla, diversa e profundamente 
estratificada, mas ainda dividida em duas grandes classes econômico-sociais. Por um lado, a nossa sociedade compõe-se da classe burguesa, ou seja, a minoria de homens que detêm o monopólio dos meios de produção; por outro lado, compõese da classe trabalhadora, isto é, a maioria dos homens que possuem apenas sua força de trabalho. Dentro da classe burguesa, existem os pequenos, os médios e os grandes proprietários dos meios de produção. Dentro da classe trabalhadora, existem homens que lidam diretamente com a produção da riqueza e homens que trabalham no ramo de serviços. Geralmente, enquanto camponeses e operários produzem a mais-valia de que a burguesia insaciavelmente se nutre, trabalhadores da classe média assumem as profissões liberais, isto é, ocupam-se das tarefas que não se ligam à produção direta da riqueza. No interior de uma sociedade estratificada como a atual, torna-se ingênuo conceber a educação das crianças de modo abstrato. Portanto, levando-se em consideração as condições concretas de vida das crianças pertencentes às famílias da classe trabalhadora, mais do que nunca os pais e os professores devem se preocupar com o papel que os produtos da indústria do entretenimento vêm cumprindo na formação dessas crianças.

$\mathrm{Na}$ introdução do presente artigo, havíamos definido que uma das principais funções da indústria do entretenimento na atualidade consiste na reprodução do espetáculo. Naquela ocasião, baseando-nos na teoria de Debord, havíamos definido o espetáculo como uma relação social mediatizada por imagens, mediação essa que possui um caráter ludibriador e normativo. Faz-se necessário, neste momento, aprofundar a definição de espetáculo:

"Considerado em sua totalidade, o espetáculo é ao mesmo tempo o resultado e o projeto do modo de produção existente. Não é um suplemento do mundo real, uma decoração que lhe é acrescentada. É o âmago do irrealismo da sociedade real. Sob todas as suas formas particulares informação ou propaganda, publicidade ou consumo direto de divertimentos -, o espetáculo constitui o modelo atual da vida dominante na sociedade. É a afirmação onipresente da escolha já feita na produção, e o consumo que decorre dessa escolha. Forma e conteúdo do espetáculo são, de modo idêntico, a justificava total das condições e dos fins do sistema existente. O espetáculo também é a presença 
permamente dessa justificativa, como ocupação da maior parte do tempo vivido fora da produção moderna" (DEBORD, 1997, p. 14-15).

Enquanto "modelo atual da vida dominante na sociedade" e "justificação total das condições e dos fins do sistema existente", o espetáculo cumpre a função de realizar a manutenção ideológica que garante a docilidade da classe trabalhadora. Essa manutenção se realiza por meio da ocupação da maior parte do tempo vivido fora da produção, isto é, nos breves períodos em que o trabalhador possui para descansar.

Nas atuais circunstâncias, boa parte dos entretenimentos emerge como produto do reino autocrático do capital mercantil. Destinados a imbecilizar $e$ docilizar as massas, os entretenimentos produzidos pela indústria do entretenimento colaboram para a formação da consciência coletiva, no sentido de trabalharem com os signos da sociedade do espetáculo. Tais signos constroem as ideias e os valores relativos à felicidade e à vida correta na sociedade moderna. $\mathrm{O}$ exemplo que melhor esclarece essa argumentação são as circunstâncias em que a Copa do Mundo da FIFA 2014 ocorreu para as comunidades das favelas das capitais brasileiras. Conforme dissemos na introdução do presente artigo, enquanto os moradores de diversas favelas foram violentamente varridos de suas casas, a maior parte da população brasileira, com a consciência anestesiada $e$ as paixões pungidas pelo ufanismo nacionalista, consumia o espetáculo futebolístico propagandeado e instigado pelos meios de comunicação de massa. De acordo com Adorno: "divertir-se significa que não devemos pensar, que devemos esquecer a dor, mesmo onde ela se mostra. Na base do divertimento planta-se a impotência" (ADORNO, 2002, p. 44). Os serviçais do capital financeiro e industrial cumpriram com inescrupuloso esmero a tarefa que lhes foi atribuída: divulgar a ideia e o sentimento de que a nação feliz é a nação que vence a Copa do Mundo da FIFA. Nesse contexto atual, o entretenimento não se limita a ser uma ocupação passiva e secundária, pois passa a formar a consciência popular e a ocupar um lugar central na vida humana. 
A indústria do entretenimento abrange o esporte, a literatura, o cinema, a pintura, a música, o brinquedo destinado às crianças, a festa, programas de televisão etc. Todas essas manifestações culturais, quando dominadas pelo espetáculo, cumprem a função de manter intactas as bases de uma sociedade que concentra a riqueza nas mãos de cada vez menos pessoas. Por essa razão, o conteúdo do entretenimento espetacularizado cumpre a função de desviar a atenção da classe trabalhadora no sentido de fazê-la não perceber a necessidade de salvar o planeta e a possibilidade de construirmos uma sociedade mais justa.

Nessa perspectiva, a alienação deixa de ser um fenômeno exclusivo da produção capitalista e passa a ser, de um modo mais abrangente, um resultado da função que o entretenimento espetacularizado cumpre nos momentos em que o trabalhador descansa e/ou consome o entretenimento na sociedade capitalista. Não obstante, urge a questão: do ponto de vista da educação da classe trabalhadora brasileira, é ou não é importante definir critérios de distinção entre os entretenimentos que deverão ou não ser empregados na escola pública e na vida cotidiana das crianças? Enquanto educadores, pensamos que, muito mais urgente do que no contexto histórico de Aristóteles, a resposta a essa questão deve ser positiva. O critério da alienação seria interessante tanto do ponto de vista da identificação dos entretenimentos de má qualidade quanto do ponto de vista da reflexão crítica que a escola pública deve realizar em relação à função ética $e$ política que tais entretenimentos cumprem na contemporaneidade.

\section{Considerações finais}

Para finalizar, respondamos objetivamente às duas questões que nos propusemos como problema do presente artigo.

Como Aristóteles concebeu a relação entre entretenimento e educação? Definindo o entretenimento como uma ocupação passiva associada aos prazeres restaurativos, e considerando o entretenimento como um elemento da educação de crianças de sete a catorze anos, Aristóteles concebeu a relação entre entretenimento e educação no sentido de apontar a música como uma espécie de 
repouso superior, repouso esse a ser destinado ao cidadão perfeito em seus momentos de descanso. É preciso lembrar que o cidadão perfeito seria adulto $e$, para melhor desfrutar do entretenimento musical, ele teria de ser instruído na arte da música durante a infância. Isso nos leva a concluir que, segundo Aristóteles, para se desfrutar um entretenimento superior, devemos ter construído certos conhecimentos desde a infância. Tais conhecimentos, do ponto de vista da música, não deveriam ser meramente técnicos, mas também morais, porquanto, como vimos, a música seria uma arte que pode produzir certos sentimentos morais nos homens.

Como devemos dimensionar a relação entre entretenimento e educação pública brasileira de um ponto de vista contemporâneo? Como vimos, não é aceitável aplicar a teoria aristotélica da relação entre entretenimento e educação à nossa realidade porque a ideia de retorno e de naturalização da escravidão é inaceitável. No entanto, é preciso levar em consideração a necessidade aristotélica de se definir um critério que distinga os entretenimentos bons dos entretenimentos ruins. Assim como na época de Aristóteles, atualmente, tal critério, por ser de natureza ética e política, deve ser fruto do posicionamento da escola pública perante a sociedade que desejamos construir. Queremos uma sociedade cativa do espetáculo ou uma sociedade que valoriza princípios éticos e verdadeiramente democráticos? Para nós, caso não queira cumprir uma função semelhante àquela que os aparelhos ideológicos burgueses têm cumprido atualmente, a escola pública brasileira deve ser um espaço de contestação do espetáculo $e$, portanto, de promoção da democracia.

\section{Referências}

ADORNO, Theodor Ludwig. Indústria cultural e sociedade. São Paulo: Paz e Terra, 2002.

ARISTÓTELES. A política. 2. ed. São Paulo: Edipro, 2009a.

. Ética a Nicômaco. 3. ed. São Paulo: Edipro, 2009b.

. Metafísica. Porto Alegre: Globo, 1969. 
AVANÇO, Leonardo Dias. Diagoguê e suas implicações na educação do cidadão em Aristóteles. 2012. 108 f. Dissertação (Mestrado em Educação) - Faculdade de Ciência e Tecnologia, Universidade Estadual Paulista, Presidente Prudente, 2012. Disponível em:

<http://www2.fct.unesp.br/pos/educacao/teses/2012/leonardo.pdf>.

BRECHT, Bertold. Aos que virão depois de nós. Disponível em: < http://www.cartamaior.com.br/?/Editoria/Midia/Aos-que-virao-depois-denos/12/7490 > . Acesso em: 20 de ago. 2014.

DEBORD, Guy. Sociedade do espetáculo. Rio de Janeiro: Contraponto, 1997.

HOURDAKIS, Antoine. Aristóteles e a educação. São Paulo: Loyola, 2001.

HUIZINGA, Johan. Homo ludens: o jogo como elemento da cultura. 5. ed. São Paulo: Perspectiva, 2008. 